\title{
Timing of endoscopic retrograde cholangiopancreatography in acute biliary pancreatitis without cholangitis: a nationwide inpatient cohort study
}

\author{
Savan Kabariaa ${ }^{a}$ Hemant Mutneja ${ }^{b}$, Michael Makara, Sushil Ahlawat ${ }^{c}$, Anish V. Pateld ${ }^{\text {, }}$ Vinod K. Rustgid, \\ Abhishek Bhurwal ${ }^{\mathrm{d}}$ \\ RBHS, Rutgers University, New Brunswick, NJ; John H. Stroger Cook Country Hospital, Chicago, Il; New Jersey \\ Medical School, RBHS, Rutgers University, USA
}

\section{Abstract}

Background The timing of endoscopic retrograde cholangiopancreatography (ERCP) in patients with acute biliary pancreatitis without cholangitis is unclear. We accessed a national database to analyze the outcomes of urgent $(<24 \mathrm{~h})$ and early $(24-72 \mathrm{~h})$ ERCP in this cohort.

Methods The cohort was extracted from the Nationwide Inpatient Sample database. Hospital ERCP volumes were generated using unique hospital identifiers. Multivariate regression modeling was used to analyze the predictors of urgent vs. early ERCP use, and to determine various outcome variables between the 2 cohorts.

Results Overall, 105,433 admissions were evaluated. There was a significant rise in urgent ERCP performed over the study period. Older patients, males, patients with comorbidities, African American and Hispanic patient populations were less likely to receive urgent ERCP. High ERCP volume hospitals, teaching hospitals, and hospitals in the Midwest and West were more likely to perform urgent ERCP. There were no differences in mortality rates or complication rates between the 2 cohorts. However, there were significant differences in length of stay and healthcare cost analysis.

Conclusions The increasing use of urgent ERCP did not result in a clinically significant benefit in terms of mortality, length of stay, or healthcare cost analysis. The use of urgent ERCP is also not uniform across various demographic and hospital cohorts. Urgent ERCP may be over-utilized, and it may be reasonable to perform ERCP in this patient population based on the physician's suspicion about the severity of disease.

Keywords Endoscopic retrograde cholangiopancreatography, acute biliary pancreatitis, national trends Ann Gastroenterol 2021; 34 (2): 1-7

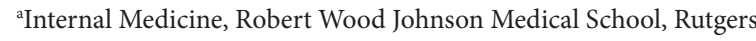
Biomedical and Health Sciences (RBHS), Rutgers University, New Brunswick, NJ (Savan Kabaria, Michael Makar, Sushil); ${ }^{\mathrm{b}}$ Gastroenterology and Hepatology, John H. Stroger Cook County Hospital, Chicago, Il (Hemant Mutneja); 'Division of Gastroenterology \& Hepatology, New Jersey Medical School, Rutgers Biomedical and Health Sciences (RBHS), Rutgers University, Newark, NJ (Sushil Ahlawat); ${ }^{\mathrm{d} D i v i s i o n}$ of Gastroenterology and Hepatology, Robert Wood Johnson School of Medicine, Rutgers Biomedical and Health Sciences (RBHS), Rutgers University, New Brunswick, NJ, (Anish V. Patel, Vinod K. Rustgi, Abhishek Bhurwal), USA

Conflict of Interest: None

Correspondence to: Savan Kabaria MD, 125 Paterson St, New Brunswick, NJ 08901, USA, e-mail: savankabaria@gmail.com

Received 17 November 2020; accepted 6 December 2020; published online 26 February 2021

DOI: https://doi.org/10.20524/aog.2021.0615

\section{Introduction}

Acute pancreatitis is one of the most common reasons for hospitalization worldwide [1]. Over the last several decades, the incidence of acute pancreatitis has been increasing [2]. Gallstones and alcohol are the most frequent causes of acute pancreatitis [1]. It has been hypothesized that gallstones lead to inflammation of the pancreas by transient obstruction of the bile duct and the pancreatic duct, which results in bile reflux and increased hydrostatic pressure in the pancreatic duct [1].

Often, acute gallstone-induced pancreatitis is self-limited and improves with conservative management. However, in specific incidences, the gallstone fails to pass spontaneously, and the subsequent persistent biliary obstruction leads to severe pancreatitis and/or cholangitis. It has been suggested, based on several animal and human models, that the duration of obstruction 
may be a critical factor contributing to the severity of pancreatitis [3-6]. Therefore, endoscopic retrograde cholangiopancreatography (ERCP) can be performed in acute biliary pancreatitis to relieve the obstruction and reduce the morbidity and mortality associated with the condition [3]. Subsequently, cholecystectomy should be performed to achieve definitive treatment $[7,8]$.

Several professional society guidelines recommend that urgent ERCP should be performed within $24 \mathrm{~h}$ for patients with acute biliary pancreatitis accompanied by cholangitis [8-12]. Based on weak evidence, the guidelines also recommend that ERCP should be considered within $72 \mathrm{~h}$ when there are signs of persistent obstruction, and it is not recommended in the absence of cholangitis or persistent biliary obstruction [7-10,13,14]. Thus, in the absence of cholangitis, the role of the timing of therapeutic ERCP $(<24 \mathrm{~h},<48 \mathrm{~h}$, or $<72 \mathrm{~h})$ remains unclear in patients with persistent biliary obstruction.

The National Inpatient Sample (NIS) is a nationally representative database containing information about hospital admissions. The NIS allows generalized access to data for patients admitted with acute biliary pancreatitis across the United States (US). There are no nationally representative data describing the outcomes of acute biliary pancreatitis in relation to the timing of ERCP. We aimed to analyze the role of ERCP timing in these patients using the NIS database. In addition, we analyzed the factors associated with urgent ERCP in acute biliary pancreatitis and evaluated the national trends over a decade.

\section{Materials and methods}

\section{Design and data source}

The study cohort was extracted from the NIS database of the Healthcare Cost and Utilization Project (HCUP), Agency for Healthcare Research and Quality (AHRQ) [15]. The NIS is the largest and most widely used source of publically available de-identified inpatient data in the US. The NIS does not require institutional review board approval or exempt determination. The database is a stratified sample of all hospital discharges in the US, excluding rehabilitation hospitals and long-term care facilities. HCUP discharge weights were used to obtain national estimates [16]. The sample averages 35 million weighed discharges every year, representing $95 \%$ of US hospitalizations [16]. We used the International Classification of Diseases, Ninth Revision, Clinical Modification (ICD-9-CM) codes for primary and secondary diagnoses to identify the study population.

\section{Study criteria}

We chose the evaluation period from 1 January 2005 to 31 December 2014, based on the availability of complete data and an adequate sample size for modeling time trends. We eliminated discharge records with missing information for the year, mortality or primary diagnosis, according to a scheme suggested by the AHRQ [17]. The inclusion criteria included acute biliary pancreatitis defined by the primary diagnosis of acute pancreatitis in patients who underwent ERCP within the first $72 \mathrm{~h}$ of admission. These patients were probably thought to have a persistent biliary obstruction, thus prompting ERCP within $72 \mathrm{~h}$ based on current guidelines. Patients with a secondary diagnosis of cholangitis were excluded, as ERCP timing is well established in this patient population. Additionally, admission to the critical care units probably represented greater severity of the disease, related to a multitude of comorbidities, while the diagnostic and therapeutic avenues pursued are also convoluted in patients with pancreatic/biliary malignancies and chronic pancreatitis. Therefore, these patient populations were omitted to avoid confounding the outcome variables, such as length of stay, cost, or procedural considerations. Patients transferred from an external healthcare facility were also excluded, as the disease course in this patient population is uncertain. Finally, patients aged $<18$ and $>89$ years were excluded. A flowchart explaining the inclusion and exclusion criteria is shown in Fig. 1.

\section{Definition of variables}

The NIS carries demographic variables that include age, sex, race, household income per patient zip-code, patient's insurance, and hospital-related variables, such as number of beds, region, teaching status and urban/rural location of the hospital, as well as outcome variables, such as length of stay, hospitalization charges, hospitalization costs, and in-hospital mortality. The patient's comorbidities were measured using the Deyo adaptation of the Charlson Comorbidity Index (CCI) for administrative data $[18,19]$. Hospitalization charges were calculated, after being adjusted for annual inflation specific to healthcare (Bureau of Labor Statistics: http:// data.bls.gov/), with the reference year 2020. Intensive Care Unit admissions were defined as patients requiring a ventilator, or medications for blood pressure support at admission. Therapeutic ERCP was defined by dilation of the duct, sphincterotomy or insertion of a stent. Other cases were classified as diagnostic ERCP. The ICD-9-CM codes used in this study have been previously validated for acute pancreatitis [2,20-23], ERCP including therapeutic and diagnostic [23-25], cholangitis [23,26], chronic pancreatitis [27], pancreatic/biliary malignancy [28], and complications after procedures $[29,30]$. All the ICD-9-CM codes used in the study are given in the Supplementary Table 1.

Unique hospital identifiers were used to generate a variable specifying the number of ERCP procedures performed at each hospital per year. Hospitals were subsequently classified according to ERCP procedure volumes per year, as low volume $(\leq 100)$, intermediate volume (101-199), or high volume $(\geq 200)$. Such a scheme has been used in a prior study to examine hospitals by ERCP volume [31].

The database offers variables to correlate the day after admission to each procedure performed during hospitalization. To distinguish urgent from early ERCP, the procedure was classified as urgent if it was performed on the day of admission or the first subsequent day, representing the first $24 \mathrm{~h}$ after admission. Similarly, the procedure was classified as early if it 


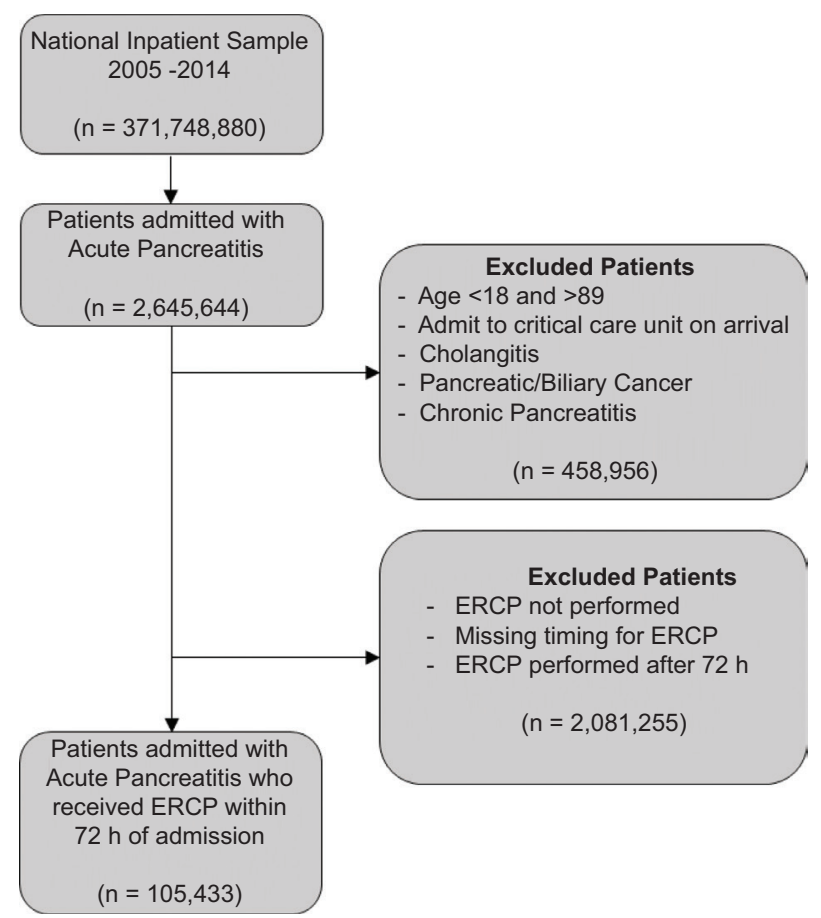

Figure 1 Flowchart detailing the cohort selection from the Nationwide Inpatient Sample. Patients with acute biliary pancreatitis who underwent endoscopic retrograde cholangiopancreatography (ERCP) within the first $72 \mathrm{~h}$ of admission were included, with specific exclusion criteria based on their secondary diagnoses

was performed on one of the following 2 days, representing 24$72 \mathrm{~h}$ after admission. This methodology has been previously used within the NIS database [32,33].

\section{Outcomes}

The primary outcome was the mortality, length of stay, hospital charges/costs, and procedural complications in the urgent and early ERCP subgroups. The secondary outcomes were the predictors of urgent ERCP, based on patient demographics and hospital characteristics, and on national temporal trends of ERCP use in acute biliary pancreatitis from 2005-2014.

\section{Statistical analysis}

We compared the baseline characteristics of the comparison group. We used the chi-squared test for categorical variables, the Student's $t$-test for normally distributed continuous variables, and the Wilcoxon rank-sum test for non-normally distributed continuous variables. Standard deviations (SD) are given for every mean value. Quartile (Q) 1 and Q3 values are indicated for every median value. Next, we performed a survey regression analysis to explore the temporal trends of urgent and early ERCP in the cohort. The trend was adjusted in relation to the ERCP hospital volume. Univariate analysis of patient demographics, hospital characteristics, and patient comorbidities, with a threshold of
Table 1 Demographics and hospital level characteristics of patients with acute biliary pancreatitis stratified by timing of ERCP

\begin{tabular}{|c|c|c|c|}
\hline \multirow[t]{3}{*}{ Characteristics } & Urgent ERCP & Early ERCP & \multirow[t]{3}{*}{ P-value } \\
\hline & $(\leq 24 \mathrm{~h})$ & $(24-72 \mathrm{~h})$ & \\
\hline & $\mathrm{n}=51,564$ & $\mathrm{n}=53,869$ & \\
\hline Female, \% & $63.40 \%$ & $60.60 \%$ & $<0.001$ \\
\hline \multicolumn{4}{|l|}{ Race/ethnicity, \% } \\
\hline Caucasian & $66.20 \%$ & $65.20 \%$ & $<0.001$ \\
\hline African American & $7.00 \%$ & $9.10 \%$ & \\
\hline Hispanic & $19.70 \%$ & $18.80 \%$ & \\
\hline $\begin{array}{l}\text { Asian or Pacific } \\
\text { Islander }\end{array}$ & $3.20 \%$ & $2.90 \%$ & \\
\hline Native American & $0.60 \%$ & $0.50 \%$ & \\
\hline Other & $3.30 \%$ & $3.50 \%$ & \\
\hline \multicolumn{4}{|l|}{ Age, $y, \%$} \\
\hline $18-29$ & $13.20 \%$ & $10.40 \%$ & $<0.001$ \\
\hline $30-39$ & $12.50 \%$ & $10.60 \%$ & \\
\hline $40-49$ & $14.50 \%$ & $12.80 \%$ & \\
\hline $50-64$ & $26.00 \%$ & $26.30 \%$ & \\
\hline $65-90$ & $33.80 \%$ & $39.90 \%$ & \\
\hline \multicolumn{4}{|l|}{ Insurance type, $\%$} \\
\hline Medicaid & $35.20 \%$ & $41.80 \%$ & $<0.001$ \\
\hline Medicare & $13.70 \%$ & $12.90 \%$ & \\
\hline Private & $42.00 \%$ & $36.60 \%$ & \\
\hline Uninsured & $9.00 \%$ & $8.70 \%$ & \\
\hline \multicolumn{4}{|l|}{ Hospital size, \% } \\
\hline Small & $9.80 \%$ & $10.30 \%$ & 0.02 \\
\hline Medium & $25.50 \%$ & $27.60 \%$ & \\
\hline Large & $64.70 \%$ & $62.20 \%$ & \\
\hline \multicolumn{4}{|l|}{ Hospital location, \% } \\
\hline Northeast & $18.60 \%$ & $20.50 \%$ & $<0.001$ \\
\hline Midwest & $19.20 \%$ & $16.10 \%$ & \\
\hline South & $34.40 \%$ & $40.70 \%$ & \\
\hline West & $27.90 \%$ & $22.70 \%$ & \\
\hline Teaching hospitals, \% & $50.50 \%$ & $46.30 \%$ & $<0.001$ \\
\hline \multicolumn{4}{|c|}{ Hospitals by yearly ERCP volumes, \% } \\
\hline Low $(<100)$ & $16.94 \%$ & $14.26 \%$ & $<0.001$ \\
\hline Intermediate (100-200) & $16.98 \%$ & $16.57 \%$ & \\
\hline High $(>200)$ & $66.08 \%$ & $69.17 \%$ & \\
\hline \multicolumn{4}{|l|}{ CCI score, \% } \\
\hline 0 & $57.90 \%$ & $51.80 \%$ & $<0.001$ \\
\hline 1 & $24.20 \%$ & $25.40 \%$ & \\
\hline 2 & $9.50 \%$ & $11.50 \%$ & \\
\hline$\geq 3$ & $8.30 \%$ & $11.40 \%$ & \\
\hline
\end{tabular}

ERCP, endoscopic retrograde cholangiopancreatography; CCI, Charlson comorbidity index 
$\mathrm{P}<0.1$, was used to generate a multivariate regression model with demographic, CCI, and hospital characteristic covariates to identify the predictors of urgent ERCP. Finally, multivariate regression models to predict the hazard ratio related to mortality and post-procedure complications, and linear regression models to predict regression coefficients related to the length of stay and hospital charges/costs were devised using significant covariates, as mentioned above. A variable defining whether the ERCP was therapeutic or diagnostic was included in the regression modeling. Analyses were performed using Stata, version 16.0 (StataCorp, College Station, TX). NIS is based on an intricate sampling design that includes stratification, clustering, and weighing. This software facilitates analysis to produce nationally representative unbiased results, variance estimates, and P-values.

\section{Results}

\section{Baseline demographic and hospital characteristics}

A total of 105,433 weighed admissions with acute biliary pancreatitis who underwent ERCP within the first $72 \mathrm{~h}$ of admission were included in the analysis of the 10-year study period (Fig. 1). Overall, the mean age of the study population was 55.7 years (SD 19 years), $62.0 \%$ were females, and there were $65.7 \%$ Caucasian, $19.3 \%$ Hispanic, and $8.0 \%$ African American patients. Patients were primarily admitted to large hospitals (63.5\%), in urban locations (94.0\%), and more frequently in the Southern US (37.5\%).

Demographic and hospital-level differences between urgent and early ERCP are presented in Table 1 . At the level of patient demographics, urgent ERCP was more common in females and younger adults. The African American population had fewer urgent ERCP performed. Patients with private insurance were over-represented and patients with Medicaid under-represented in the urgent ERCP cohort. There were no significant differences based on the income level of the patient's zip code or the location of the hospital (data not shown). Hospital level characteristics were dissimilar in the 2 cohorts. Larger teaching institutions and hospitals in the West and Midwest had a higher number of urgent ERCP procedures documented. Additionally, intermediate- and high-volume hospitals (based on ERCP procedures performed each year) had greater numbers of urgent ERCP procedures.

The overall mortality rate in the cohort was $0.51 \%$. The median length of stay was 4 days (Q1 4 days; Q3 6 days). Median hospitalization costs and charges were \$14,539 (Q1 \$10,248; Q3 \$20,375) and \$35,624 (Q1 \$22,707; Q3 \$55,741), respectively. Overall complication rates were $3.77 \%$, subdivided into infectious $(0.2 \%)$, urinary $(0.2 \%)$, pulmonary $(1.5 \%)$, and gastrointestinal (1.7\%).

\section{Trends of urgent ERCP in acute biliary pancreatitis patients}

The total number of ERCPs performed in acute biliary pancreatitis patients in our cohort increased from 9727 in 2005 to 10,710 in 2014 . The total number of urgent ERCP procedures also increased, from 4601 in 2005 to 5620 in 2014 . The total number of early ERCP procedures was largely unchanged, from 5126 in 2005 to 5090 in 2014 . The overall trend between urgent and early ERCP in acute biliary pancreatitis patients over the 10 years is depicted in Fig. 2. There was a significant increasing trend in the use of urgent ERCP procedures over the 10-year study period from 2005-2014 ( $\mathrm{P}$ for trend $<0.001$ ).

\section{Predictors of urgent ERCP in acute biliary pancreatitis patients}

Various predictors of urgent ERCP in acute biliary pancreatitis patients in the multivariate regression model are shown in Table 2. Older patients, males, patients with a high number of comorbidities, and African American and Hispanic patients were significantly less likely to undergo urgent ERCP. High-volume hospitals by ERCP were more likely to perform urgent ERCP, as were teaching hospitals and hospitals in the Midwestern and Western US states.

\section{Outcomes of urgent ERCP in acute biliary pancreatitis patients}

Various outcome variables and their respective multivariate hazard ratios and regression coefficients after urgent ERCP, compared to early ERCP, are presented in Table 3. There were no significant differences in mortality rates or complication rates. A composite variable encompassing all complications (infectious, urinary, pulmonary, and gastrointestinal) did not differ significantly between the 2 groups.

There were significant differences in length of stay: 5.1 days (95\% confidence interval [CI] 5.0-5.2) for urgent ERCP vs. 5.9 days (95\%CI 5.8-6.0) for early ERCP; total hospitalization costs: $\$ 17,912$ (95\%CI $\$ 17,504-18,283)$ for urgent ERCP vs.

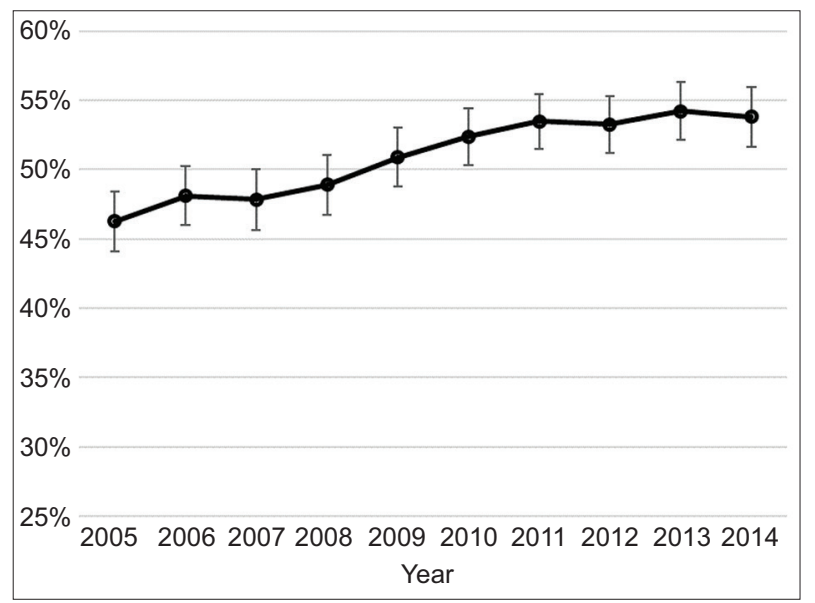

Figure 2 The rising trend in the use of urgent $(\leq 24 \mathrm{~h})$ endoscopic retrograde cholangiopancreatography (ERCP) in the United States hospitals over the study period ( $\mathrm{P}$ trend $<0.001$ ). The corresponding rate of early ERCP (24-72 h) is represented by 1 - urgent ERCP rate 
Table 2 Multivariate regression model predicting urgent ERCP $(\leq 24$ h) in patients with acute biliary pancreatitis

\begin{tabular}{|c|c|c|}
\hline Variables & $\begin{array}{l}\text { Odds ratio } \\
(95 \% \mathrm{CI})\end{array}$ & P-value \\
\hline \multicolumn{3}{|l|}{$\begin{array}{l}\text { Hospitals by yearly ERCP } \\
\text { volumes }\end{array}$} \\
\hline Low $(<100)$ & ref & \\
\hline Intermediate (100-200) & $1.09(0.98-1.21)$ & 0.085 \\
\hline High $(>200)$ & $1.13(1.03-1.23)$ & 0.005 \\
\hline \multicolumn{3}{|l|}{ Sex } \\
\hline Male & ref & \\
\hline Female & $1.07(1.01-1.14)$ & 0.027 \\
\hline \multicolumn{3}{|l|}{ Race } \\
\hline Caucasian & ref & \\
\hline African American & $0.74(0.66-0.82)$ & $<0.001$ \\
\hline Hispanic & $0.89(0.82-0.97)$ & 0.007 \\
\hline Asian or Pacific Islander & $0.93(0.80-1.11)$ & 0.45 \\
\hline Native American & $0.96(0.62-1.48)$ & 0.86 \\
\hline Other & $0.87(0.74-1.02)$ & 0.10 \\
\hline \multicolumn{3}{|l|}{ Age } \\
\hline $18-29$ & ref & \\
\hline $30-39$ & $0.97(0.86-1.1)$ & 0.72 \\
\hline $40-49$ & $0.90(0.80-1.01)$ & 0.11 \\
\hline $50-64$ & $0.83(0.74-0.92)$ & 0.001 \\
\hline $65-90$ & $0.77(0.67-0.88)$ & $<0.001$ \\
\hline \multicolumn{3}{|l|}{ Region } \\
\hline Northeast & ref & \\
\hline Midwest & $1.23(1.11-1.35)$ & 0.001 \\
\hline South & $0.96(0.89-1.05)$ & 0.44 \\
\hline West & $1.42(1.30-1.55)$ & $<0.001$ \\
\hline \multicolumn{3}{|l|}{ Hospital location } \\
\hline Rural & ref & \\
\hline Urban & $0.94(0.82-1.07)$ & 0.37 \\
\hline \multicolumn{3}{|l|}{ Teaching status } \\
\hline Non-teaching & ref & \\
\hline Teaching & $1.18(1.11-1.26)$ & $<0.001$ \\
\hline \multicolumn{3}{|l|}{ CCI score, \% } \\
\hline 0 & ref & \\
\hline 1 & $0.91(0.84-0.97)$ & 0.01 \\
\hline 2 & $0.80(0.66-0.81)$ & $<0.001$ \\
\hline$\geq 3$ & $0.74(0.72-0.88)$ & $<0.001$ \\
\hline
\end{tabular}

ERCP, endoscopic retrograde cholangiopancreatography; CI, confidence interval; CCI, Charlson comorbidity index

$\$ 18,599$ (95\%CI $\$ 18,226-18,972$ ) for early ERCP; and total hospitalization charges: $\$ 47,670$ (95\%CI $\$ 46,549-48,792$ ) for urgent ERCP vs. $\$ 49,804$ (95\%CI $\$ 48,680-50,928$ ) for early ERCP. Representative P-values are shown in Table 3.

\section{Discussion}

Multiple prior studies demonstrated that urgent ERCP in acute biliary pancreatitis, without evidence of cholangitis, did not show better clinical outcomes, such as mortality, organ failure, infected pancreatic and peripancreatic necrosis, or total rates of necrotizing pancreatitis [34-42]. The evidence is still considered to be of low quality, given the inclusion of heterogeneous populations, single-center studies, outdated practices, and more importantly, an insufficient power to detect a difference $[7,9]$. In this study, we showed an increasing trend in the use of urgent ERCP over the study period in patients presenting with acute biliary pancreatitis without evidence of cholangitis in the US. This suggests a lack of adoption of the recommendations based on the studies described previously. The lack of concrete evidence could be the basis for higher numbers of urgent ERCPs being performed without an appropriate indication. Therefore, we aimed to evaluate the role of the timing of ERCP in acute biliary pancreatitis using the NIS, the largest publicly available database in the US. Our cohort of 105,433 acute biliary pancreatitis patients who underwent ERCP is the largest cohort of patients used to examine this phenomenon.

We show that urgent ERCP was not clinically superior to early ERCP performed within $72 \mathrm{~h}$ of admission, in regard to mortality and complication rates. Despite statistically significant differences in length of stay and hospitalization costs/charges, the differences in these outcome measures can be considered clinically modest, and the decision to pursue urgent rather than early ERCP can be made on an individualized clinical basis.

Our study suggests that there are social and regional disparities in the management of acute biliary pancreatitis patients. African American patients had substantially less access to urgent ERCP compared to Caucasian patients, while Hispanic patients showed a modest deficit. Lower ERCP rates have been previously correlated in the African American population [43,44]. However, the mechanisms of these disparities remain unclear. African Americans may have severe pancreatitis, which could be a reason to avoid ERCP initially [45]. Regionally, there is no current evidence to suggest higher rates of urgent ERCP in Midwestern and Western US states. A possible explanation could be the concentration of high volume, tertiary care centers in the Northeast, which could provide a multidisciplinary approach as compared to the other regions. Further investigation needs to be pursued to identify if these racial and regional trends continue, and conformance with the national averages and best practice guidelines should be encouraged. Additionally, patients with one or more comorbidities and older patient populations were less likely to undergo urgent ERCP, probably because of a higher perceived risk of complications of the procedure and anesthesia. Moreover, teaching hospitals were more likely to pursue urgent ERCPs, probably because they had more trained staff available to perform the procedure.

Notably, there are certain limitations to our study. There is no information available on laboratory values in the dataset. Consequently, the clinical decision making in regard to the timing of ERCP is often ambiguous and challenging to capture in such a dataset. Hence, this remains a significant limitation in our retrospective study, as well as in other randomized clinical 
Table 3 Multivariate hazard ratio and regression coefficient outcomes after urgent ERCP compared to early ERCP in patients with acute biliary pancreatitis

\begin{tabular}{lcc}
\hline Variables & Hazard ratio $(95 \% \mathrm{CI})$ & P-value \\
\hline Mortality & $1.14(0.76-1.71)$ & 0.52 \\
Overall complications & $1.05(0.90-1.22)$ & 0.53 \\
Infectious & $0.59(0.30-1.14)$ & 0.12 \\
Urinary & $1.05(0.60-1.88)$ & 0.85 \\
Pulmonary & $1.00(0.79-1.26)$ & 0.98 \\
Gastrointestinal & $1.02(0.82-1.29)$ & 0.82 \\
\hline Variables & Regression coefficient $(95 \% \mathrm{CI})$ & P-value \\
\hline Length of stay, day & $(-0.71)[(-0.85)-(-0.57)]$ & $<0.001$ \\
Total charges, \$ & $\$(-2,134)[\$(-3,730)-\$(-537)]$ & $<0.001$ \\
Total costs, \$ & $\$(-687)[\$(-1,216)-\$(-158)]$ & $<0.001$ \\
\hline
\end{tabular}

ERCP, endoscopic retrograde cholangiopancreatography; CI, confidence interval

trials, as previously described [10]. Moreover, ERCP procedures performed outside of the 72-h window were excluded and could further represent non-adherence to evidence-based guidelines. Additionally, it can also be argued that patients in the cohort who underwent urgent ERCP probably had more evidence of biliary obstruction than their counterparts. The severity of obstruction, however, cannot be determined using our cohort. Consequently, our regression analysis included the outcome of the ERCP in regard to therapeutic vs. non-therapeutic (diagnostic) ERCP as a confounding factor. By using this balancing variable, we were able to compare urgent therapeutic ERCPs with early therapeutic ERCPs. The conclusions of the study are strengthened by the absence of significant differences in the outcome variables after adjustment for the ERCP outcomes.

Despite the limitations, our dataset has multiple strengths that increase our confidence in the veracity of our results. The NIS is the largest all-payer database of hospital discharges in the US and is representative of all regions throughout the country. Therefore, our findings have excellent external validity and are generalizable to the US population hospitalized with acute biliary pancreatitis. Our cohort provides the largest dataset of acute biliary pancreatitis patients to detect a difference between urgent and early ERCP use. Because of the large cohort size, we can accurately detect differences in the outcome variables, which has been cited as a limitation in smaller prior retrospective studies and clinical trials. We are also able to meaningfully control for demographics and hospital-level characteristics while examining the outcome variables. Finally, we also compared outcomes across hospitals based on ERCP volumes, which contributes to the novelty of our findings.

The results from our retrospective cohort of patients provide further evidence to strengthen the current guidelines, which have recommended that ERCP should be performed within $72 \mathrm{~h}$ of hospitalization in cases of acute biliary pancreatitis without cholangitis. By demonstrating similar outcomes among urgent and early ERCP patients, we show that patient care can be individualized, and the timing of ERCP should be based on the resource availability at a particular institution and the particular clinical scenario. Future clinical trials should aim at defining strict inclusion and exclusion criteria with clear definitions for persistent biliary obstruction and cholangitis, as well as identifying the role of imaging modalities for proper triage of acute biliary pancreatitis patients.

\section{Summary Box}

\section{What is already known:}

- Urgent (within $24 \mathrm{~h}$ ) endoscopic retrograde cholangiopancreatography (ERCP) should be performed for patients with acute biliary pancreatitis accompanied by cholangitis

- The timing of ERCP in patients with acute biliary pancreatitis without cholangitis is not known

\section{What the new findings are:}

- There is a rising trend in the use of urgent ERCP in patients with acute biliary pancreatitis without cholangitis

- Urgent ERCP is not uniformly utilized across different hospitals and patient cohorts

- Urgent ERCP and early ERCP (within 72 h) have similar clinical outcomes in this patient population

\section{References}

1. Frakes JT. Biliary pancreatitis: a review. Emphasizing appropriate endoscopic intervention. J Clin Gastroenterol 1999;28:97-109.

2. Krishna SG, Kamboj AK, Hart PA, Hinton A, Conwell DL. The changing epidemiology of acute pancreatitis hospitalizations: a decade of trends and the impact of chronic pancreatitis. Pancreas 2017;46:482-488.

3. Acosta JM, Rubio Galli OM, Rossi R, Chinellato AV, Pellegrini CA. Effect of duration of ampullary gallstone obstruction on severity of lesions of acute pancreatitis. J Am Coll Surg 1997;184:499-505.

4. Hirano T, Manabe T. A possible mechanism for gallstone pancreatitis: repeated short-term pancreaticobiliary duct obstruction with exocrine stimulation in rats. Proc Soc Exp Biol Med 1993;202:246-252.

5. Rünzi M, Saluja A, Lerch MM, Dawra R, Nishino H, Steer ML. Early ductal decompression prevents the progression of biliary pancreatitis: an experimental study in the opossum. Gastroenterology 1993;105:157-164.

6. Senninger N, Moody FG, Coelho JC, Van Buren DH. The role of biliary obstruction in the pathogenesis of acute pancreatitis in the opossum. Surgery 1986;99:688-693.

7. Tenner S, Baillie J, DeWitt J, Vege SS; American College of Gastroenterology. American College of Gastroenterology guideline: management of acute pancreatitis. Am J Gastroenterol 2013;108:1400-1415; 1416.

8. Working Group IAP/APA Acute Pancreatitis Guidelines. IAP/ APA evidence-based guidelines for the management of acute 
pancreatitis. Pancreatology 2013;13(4 Suppl 2):e1-e15.

9. Crockett SD, Wani S, Gardner TB, Falck-Ytter Y, Barkun AN; American Gastroenterological Association Institute Clinical Guidelines Committee. American Gastroenterological Association Institute guideline on initial management of acute pancreatitis. Gastroenterology 2018;154:1096-1101.

10. Vege SS, DiMagno MJ, Forsmark CE, Martel M, Barkun AN. Initial medical treatment of acute pancreatitis: American Gastroenterological Association Institute technical review. Gastroenterology 2018;154:1103-1139.

11. Parikh MP, Wadhwa V, Thota PN, Lopez R, Sanaka MR. Outcomes associated with timing of ERCP in acute cholangitis secondary to choledocholithiasis. J Clin Gastroenterol 2018;52:e97-e102.

12. Khashab MA, Tariq A, Tariq U, et al. Delayed and unsuccessful endoscopic retrograde cholangiopancreatography are associated with worse outcomes in patients with acute cholangitis. Clin Gastroenterol Hepatol 2012;10:1157-1161.

13. Fogel EL, Sherman S. ERCP for gallstone pancreatitis. N Engl J Med 2014;370:150-157.

14. Tse F, and Yuan Y. Early routine endoscopic retrograde cholangiopancreatography strategy versus early conservative management strategy in acute gallstone pancreatitis. Cochrane Database Syst Rev 2012;(5):CD009779.

15. HCUP Databases. Healthcare Cost and Utilization Project (HCUP). 2006-2009. Agency for Healthcare Research and Quality, Rockville, MD. Available from: www.hcup-us.ahrq.gov/databases. jsp [Accessed 28 January 2021].

16. Trend Weights for 1993-2011 HCUP NIS Data. Healthcare Cost and Utilization Project (HCUP). 2015. Agency for Healthcare Research and Quality, Rockville, MD. Available from: www.hcup-us.ahrq. gov/db/nation/nis/trendwghts.jsp [Accessed 28 January 2021].

17. Houchens R. Missing Data Methods for the NIS and the SID. 2015. HCUP Methods Series Report \# 2015-01 ONLINE. January 22, 2015. U.S. Agency for Healthcare Research and Quality. Available from: http://www.hcup-us.ahrq.gov/reports/methods/methods.jsp [Accessed 28 January 2021].

18. D'Hoore W, Bouckaert A, Tilquin C. Practical considerations on the use of the Charlson comorbidity index with administrative data bases. J Clin Epidemiol 1996;49:1429-1433.

19. Charlson M, Szatrowski TP, Peterson J, Gold J. Validation of a combined comorbidity index. J Clin Epidemiol 1994;47:1245-1251.

20. Malli A, Durkin C, Groce JR, Hinton A, Conwell DL, Krishna SG. Unavailability of endoscopic retrograde cholangiography adversely impacts hospital outcomes of acute biliary pancreatitis: a national survey and propensity-matched analysis. Pancreas 2020;49:39-45.

21. Chaudhary F, Albeiruti R, Alqahtani F, Alhajji M, Lerfald N, Hutson W. Temporal trends and predictors of pancreatitis patients who leave against medical advice: a nationwide analysis. Gastroenterology Res 2020;13:58-65.

22. Singla A, Simons J, Li Y, et al. Admission volume determines outcome for patients with acute pancreatitis. Gastroenterology 2009;137:1995-2001.

23. James PD, Kaplan GG, Myers RP, et al. Decreasing mortality from acute biliary diseases that require endoscopic retrograde cholangiopancreatography: a nationwide cohort study. Clin Gastroenterol Hepatol 2014;12:1151-1159.

24. Schulman AR, Abougergi MS, Thompson CC. Assessment of the July effect in post-endoscopic retrograde cholangiopancreatography pancreatitis: Nationwide Inpatient Sample. World J Gastrointest Endosc 2017;9:296-303.

25. Ahmed M, Kanotra R, Savani GT, et al. Utilization trends in inpatient endoscopic retrograde cholangiopancreatography (ERCP): A crosssectional US experience. Endosc Int Open 2017;5:E261-E271.

26. Jamal MM, Yamini D, Singson Z, Samarasena J, Hashemzadeh M, Vega KJ. Decreasing hospitalization and in-hospital mortality related to cholangitis in the United States. JClin Gastroenterol 2011;45:e92-e96.
27. Adejumo AC, Adejumo KL, Pani LN. Risk and outcomes of Clostridium difficile infection with chronic pancreatitis. Pancreas 2019;48:1041-1049.

28. Mehta VV, Friedmann P, McAuliffe JC, Muscarella P, 2nd, and In $\mathrm{H}$. Pancreatic cancer surgery following emergency department admission: understanding poor outcomes and disparities in care. $J$ Gastrointest Surg 2020 May 6 [Online ahead of print]. doi: 10.1007/ s11605-020-04614-6

29. Guller U, Hervey S, Purves H, et al. Laparoscopic versus open appendectomy: outcomes comparison based on a large administrative database. Ann Surg 2004;239:43-52.

30. Kuduva Rajan S, Madireddy S, Jaladi PR, et al. Burdens of postoperative infection in endoscopic retrograde cholangiopancreatography inpatients. Cureus 2019;11:e5237.

31. Varadarajulu S, Kilgore ML, Wilcox CM, Eloubeidi MA. Relationship among hospital ERCP volume, length of stay, and technical outcomes. Gastrointest Endosc 2006;64:338-347.

32. Abougergi MS, Travis AC, Saltzman JR. Impact of day of admission on mortality and other outcomes in upper GI hemorrhage: a nationwide analysis. Gastrointest Endosc 2014;80:228-235.

33. Abbas A, Brar TS, Zori A, Estores DS. Role of early endoscopic evaluation in decreasing morbidity, mortality, and cost after caustic ingestion: a retrospective nationwide database analysis. Dis Esophagus 2017;30:1-11.

34. Fan ST, Lai EC, Mok FP, Lo CM, Zheng SS, Wong J. Early treatment of acute biliary pancreatitis by endoscopic papillotomy. $N$ Engl $J$ Med 1993;328:228-232.

35. Fölsch UR, Nitsche R, Lüdtke R, Hilgers RA, Creutzfeldt W. Early ERCP and papillotomy compared with conservative treatment for acute biliary pancreatitis. The German Study Group on Acute Biliary Pancreatitis. N Engl J Med 1997;336:237-242.

36. Oría A, Cimmino D, Ocampo C, et al. Early endoscopic intervention versus early conservative management in patients with acute gallstone pancreatitis and biliopancreatic obstruction: a randomized clinical trial. Ann Surg 2007;245:10-17.

37. Acosta JM, Katkhouda N, Debian KA, Groshen SG, Tsao-Wei DD, Berne TV. Early ductal decompression versus conservative management for gallstone pancreatitis with ampullary obstruction: a prospective randomized clinical trial. Ann Surg 2006;243:33-40.

38. Neoptolemos JP, Carr-Locke DL, London NJ, Bailey IA, James D, Fossard DP. Controlled trial of urgent endoscopic retrograde cholangiopancreatography and endoscopic sphincterotomy versus conservative treatment for acute pancreatitis due to gallstones. Lancet 1988;2:979-983.

39. Zhou MQ, Li NP, Lu RD. Duodenoscopy in treatment of acute gallstone pancreatitis. Hepatobiliary Pancreat Dis Int 2002;1:608-610.

40. Chen P, Hu B, Wang C, Kang Y, Jin X, Tang C. Pilot study of urgent endoscopic intervention without fluoroscopy on patients with severe acute biliary pancreatitis in the intensive care unit. Pancreas 2010;39:398-402.

41. Yang P, Feng KX, Luo H, Wang D, Hu ZH. Acute biliary pancreatitis treated by early endoscopic intervention. Panminerva Med 2012;54:65-69.

42. Lee HS, Chung MJ, Park JY, et al. Urgent endoscopic retrograde cholangiopancreatography is not superior to early ERCP in acute biliary pancreatitis with biliary obstruction without cholangitis. PLoS One 2018;13:e190835.

43. Nguyen GC, Tuskey A, Jagannath SB. Racial disparities in cholecystectomy rates during hospitalizations for acute gallstone pancreatitis: a national survey. Am J Gastroenterol 2008;103:2301-2307.

44. Tavakkoli A, Singal AG, Waljee AK, et al. Regional and racial variations in the utilization of endoscopic retrograde cholangiopancreatography among pancreatic cancer patients in the United States. Cancer Med 2019;8:3420-3427.

45. Munigala S, Yadav D. Case-fatality from acute pancreatitis is decreasing but its population mortality shows little change. Pancreatology 2016;16:542-550. 


\section{Supplementary material}

Supplementary Table 1 ICD-9 Codes for respective diagnoses and procedures

\begin{tabular}{lc}
\hline Acute pancreatitis & 557.0 \\
\hline ERCP-all & $51.10,51.11,51.81,51.82,51.83$, \\
& $51.84,51.85,51.86,51.87,51.88$, \\
& $52.13,52.14,52.21,52.92,52.93$, \\
& $52.94,52.97,52.98$ \\
\hline ERCP-therapeutic & $51.81,51.82,51.83,51.84,51.85$, \\
& $51.86,51.87,51.88,52.13,52.14$, \\
Cholangitis & $52.21,52.92,52.94,52.97,52.98$ \\
Chronic pancreatitis & 576.1 \\
Pancreatic/biliary malignancy & 577.1 \\
Complications & 156,157 \\
Infectious & $998.5,998.59,998.51$ \\
Urinary & 997.5 \\
Pulmonary & $997.3,518.5,512.1,518.5,518.4$ \\
Gastrointestinal & 997.4 \\
ICU admissions & $96.7,96.04,00.17$ \\
\hline
\end{tabular}

